\title{
Identification and Optimization of New Leads for Malaria Vector Control
}

\author{
Ottmar F. Hueterª, Mark Hoppéb, Philip Wege ${ }^{c}$, and Peter Maienfisch ${ }^{\star d}$
}

\begin{abstract}
A significant proportion of the world's population remains at risk from malaria, and whilst great progress has been made in reducing the number of malaria cases globally through the use of vector control insecticides, these gains are under threat from the emergence of insecticide resistance. The spread of resistance in the vector populations, principally to pyrethroids, is driving the need for the development of new tools for malaria vector control. In order to identify new leads 30,000 compounds from the Syngenta corporate chemical collection were tested in a newly developed screening platform. More than 3000 compounds (10\%) showed activity at $\leq 200$ $\mathrm{mg}$ active ingredient (Al) litre ${ }^{-1}$ against Anopheles stephensi. Further evaluation resulted in the identification of 12 viable leads for the control of adult mosquitoes, most originating from current or former insecticide projects. Surprisingly, one of these leads emerged from a former PPO herbicide project and one from a former complex III fungicide project. This indicates that representatives of certain herbicide and fungicide projects and modes of action can also represent a valuable source of leads for malaria vector control. Optimization of the diphenyl ether lead 1 resulted in the identification of the cyano-pyridyl compound $\mathbf{3 1}$. This compound $\mathbf{3 1}$ exhibits good activity against mosquito species including rdl resistant Anopheles. It is only slightly weaker than permethrin and does not show relevant levels of cross-resistance to the organochlorine insecticide dieldrin.
\end{abstract}

Keywords: Adult mosquito screening $\cdot$ Aedes $\cdot$ Anopheles $\cdot$ Diphenyl ether $\cdot$ Malaria $\cdot$ New leads · Vector control

\section{Introduction}

Malaria is a life-threatening disease caused by parasites that are transmitted to humans through the bites of infected female mosquitoes of the Anopheles genus, the so-called 'malaria vectors'. Today, a significant proportion of the world's population remains at risk from vector-borne disease. Vector control is a key intervention of disease prevention and is included as a major component of global initiatives such as the Roll Back Malaria Global Strategic Plan 2005-2015 ${ }^{[1,2]}$ and is addressed in the WHO Global Plan for Insecticide Resistance Management (2012). [3]

In 2009 Syngenta started an R\&D partnership with the Innovative Vector Control Consortium (IVCC) aiming to deliver a new insecticide for malaria vector control. The IVCC is a Product Development Partnership that aims to bring new malar-

${ }^{*}$ Correspondence: Prof. Dr. P. Maienfisch ${ }^{d}$ Dr. O. F. Hueter

E-mail: peter.maienfisch@syngenta.com, ottmar.hueter@syngenta.com Syngenta Crop Protection AG

alnsecticide Research Chemistry, Stein Research Centre, Schaffhauserstrasse, $\mathrm{CH}-4332$ Stein, Switzerland 'Insecticide Research Biology, Stein Research Centre, Schaffhauserstrasse, $\mathrm{CH}-4332$ Stein, Switzerland ${ }^{\circ}$ Chemical Research Biology, Jealott's Hill International Research Centre, Bracknell, Berkshire, RG42 6EY, UK

${ }^{d}$ Crop Protection Research, Schwarzwaldallee 215, $\mathrm{CH}-4002$ Basel, Switzerland ia vector control solutions to the market, with funding and support from many of the world's leading innovation funders, including the Bill \& Melinda Gates Foundation.

Currently, the primary interventions in malaria vector control are indoor residual wall sprays (IRS) and insecticide treated nets (ITNs) within coordinated malaria control campaigns. These campaigns are being compromised by insecticide resistance in the vector populations, principally to pyrethroids. ${ }^{[4]}$ It is notable that the most recent active ingredient used in ITNs, the pyrethroid etofenprox, was launched 29 years ago in 1987. Since then no new active ingredients have been developed for this malaria vector control market. Furthermore, current ITN and IRS market products belong to only four chemical classes, representing two distinct modes of actions (acetylcholine esterase inhibitors and voltage-gated sodium channels modulaters), and as a result resistance to these compounds is increasing.

Our research program was designed to deliver a novel adulticide for Anopheles mosquito control with the following product characteristics:

- Novel chemical class for malaria vector control with a distinct mode of action

- Activity against all relevant mosquito species

- Low or no cross-resistance with existing metabolic and altered target-site resistance mechanisms

- Applicable as IRS and in ITNs
- Potential to deliver cost-effective control and an affordable and accessible solution in malaria endemic countries

- Acceptable toxicological and environmental properties

In this article we describe our research approach which started with the development and validation of a screening platform which was subsequently used to perform a smart screening of the Syngenta corporate chemical compound library building on the experience of a range of chemists and biologists and supported by in-depth in-house knowledge on the chemistries, chemo-informatics searches and docking studies. This screening campaign resulted in numerous leads which were analysed and characterised against our target product characteristics. An overview of the subsequent optimization of one of the identified leads is also included in this paper.

\section{Development and Validation of a Screening Platform}

A novel product for the control of Anopheles mosquitoes, applicable for IRS treatment and in ITNs, needs to be active against adult mosquitoes, to possess contact activity and to provide knockdown effects and long-lasting control. These key requirements needed to be considered in the development of the screening platform.

A significant difference between the delivery of insecticidal treatments for the 
control of phytophagous insects and mosquitoes is in the potential routes of uptake of insecticidal compounds. Insecticides can reach their target site within a phytophagous insect via the oral and dermal routes. However, our initial work indicated that many chemistries previously thought to be effective via both routes of uptake were in reality largely dependent on oral uptake.

\subsection{Bioassays Using Adult Aedes aegypti and Anopheles stephensi}

To evaluate a large number of compounds for mosquito adulticidal activity, a bioassay must have a number of features:

- The bioassay should expose adult mosquitoes to the compounds in a realistic fashion. The fact that in the prevention of malaria transmission, adult mosquitoes are generally exposed to insecticides via tarsal contact when they alight upon treated nets or walls needs to be considered.

- The assay system should not intrinsically impact the health or behaviour of the mosquitoes for the duration of the study.

- The biological results should be reproducible.

- The assay should be amenable to high throughput techniques and technologies.

A methodology was developed to mimic the tarsal contact route of exposure in which adult mosquitoes were retained in the wells of 12-well PVC tissue culture plates, where the base of the wells had been treated with the compounds under evaluation. Five adult female mosquitoes, three to five days old and non-blood fed, were lightly anaesthetised with carbon dioxide and placed in a treated well. A retaining lid was used to prevent escape once the mosquitoes had recovered from the anaesthetic. The infested plates were held with the base at an angle of $60^{\circ}$ to the horizontal, to encourage mosquitoes to rest on the treated surface. The mosquitoes were assessed for knockdown one hour after introduction by looking through the clear base of the treated tissue culture plate. A mosquito was said to be knocked down if it was unable to right itself when lying on its back or side. After mosquitoes had been assessed for knockdown, a small quantity of $10 \%$ sucrose solution was provided as source of food and water. The plates were then placed at an angle of $60^{\circ}$ to the horizontal in a controlled environment chamber at $26{ }^{\circ} \mathrm{C}$ and $60 \%$ relative humidity. Mortality was assessed 24 and $48 \mathrm{~h}$ after introduction of the mosquitoes. A mosquito was recorded as 'dead' if it was unable to right itself when knocked onto its back or side. Any behavioural or physiological changes at each assessment interval were also recorded. To facilitate an evaluation of the relative insecticidal activity of the experimental compounds, a dose response was utilised. Each compound was applied at four rates with a logarithmic dilution, namely at concentrations of 200, 20, 2 and $0.2 \mathrm{mg}$ active ingredient (AI) litre $^{-1}$. Results were recorded as $\mathrm{LC}_{80}$ values indicating the lowest concentration where at least $80 \%$ of the mosquitoes were dead.

During assay development it was found that the lowest application rate of the alpha-cyano pyrethroids, such as lambda-cyhalothrin or deltamethrin, which consistently caused $100 \%$ mortality, was $0.2 \mathrm{mg}$ AI litre $^{-1}$ in the applied solution, whilst DDT was found to require a rate of $20 \mathrm{mg} \mathrm{AI} \mathrm{litre}{ }^{-1}$. It was decided that compounds less potent than DDT would not be suitable for further development. However, a rate of $200 \mathrm{mg} \mathrm{AI} \mathrm{litre}{ }^{-1}$ was included in order to ensure that weak actives from potentially fruitful areas of chemistry were not excluded.

A series of validation studies were undertaken using a range of insecticides chosen to provide a spectrum of fast, e.g. lambda-cyhalothrin, and slow, e.g. chlorfenapyr, activity. To ensure that the assay system provided consistent results both within and between studies, each insecticide was replicated ten times in a given assay, and the assay was repeated in each of six consecutive weeks. Analysis of the data generated showed that the method provided a consistent ranking of insecticides, both within a study, and between studies. The control mortality was minimal with $<1 \%$ observed over the entire study.

A tiered approach to screening the input collection was taken. All compounds were initially evaluated against an insecticide susceptible strain of Aedes aegypti. Any compounds that caused $100 \%$ knockdown or mortality at the $200 \mathrm{mg}$ AI litre ${ }^{-1}$ rate were retested against a pyrethroid susceptible strain of Anopheles stephensi.

The design of the plate-based assay facilitated automation of the chemical application. Together with the ease of infestation and assessment, more than 400 experimental compounds per week could be evaluated.

\section{Lead Identification}

Our primary screens as described above were used to test more than 30,000 compounds selected from the Syngenta corporate chemical collection. A holistic and inclusive approach was used in generating prospective inputs for our vector control screens with compounds selected from all current and terminated insecticide projects, legacy insecticide projects and selected historic fungicide and herbicide projects. For the selection of the specific compounds for biological testing against mosquitoes analysis of Syngenta screening data, including legacy company screening data as well as information from corporate projects documents and physical chemical properties together with knowledge-based judgement of chemists and biologists within Syngenta were applied.

\subsection{Results}

More than 3000 compounds (10\%) of the compounds tested showed biological activity at $200 \mathrm{mg}$ AI litre ${ }^{-1}$. The actives were clustered by chemistry and the most efficacious compound(s) by cluster evaluated against a set of criteria defined for a viable lead:

- Novel chemistry with a new mode of action for malaria vector control.

- Activity at $\leq 20 \mathrm{mg}$ AI litre ${ }^{-1}$ against both mosquito species Aedes aegypti and Anopheles stephensi. Knockdown activity was regarded as desirable but not a requirement.

- Several close analogues found to be active at $\leq 200 \mathrm{mg}$ AI litre ${ }^{-1}$.

- Resistance risks considered to be manageable.

- Physical-chemical properties in the required range considering contact activity and potential uses in IRS or as ITNs including thermostablility for polymer incorporation.

- Chemical scope for optimization and new innovations.

- Potential to develop intellectual property at least for the intended vector control uses and no detrimental freedom to operate issues.

- Cost of goods vs. efficacy likely in an acceptable range.

- Favourable initial view on human safety based on preliminary mode of action knowledge.

Our evaluation of the Syngenta corporate compounds collection resulted in the identification of a series of viable leads for the control of adult mosquitoes. Fig. 1 shows a selection of the identified leads, and their detailed biological results against Aedes aegypti and Anopheles stephensi are shown in Table 1.

It is remarkable and unexpected that our screening efforts resulted in such a large number of diverse leads, each offering a good starting point for the search of new malaria vector control agents. The lead structures shown in Fig. 1 represent twelve chemical classes and belong to six known mode of action classes, namely protoporphyrinogen oxidase (PPO) inhibitors, GABA-gated chloride channel blockers, sodium channel modulators, uncouplers of oxidative phosphorylation, mitochondrial complex I electron transport inhibitors, mitochondrial complex III electron trans- 
<smiles>O=[N+]([O-])c1cccc(Oc2c(F)cc(C(F)(F)F)cc2Cl)c1</smiles>

Lead 1

Origin: IC

EP 3550491990 [5] $\mathrm{LC}_{80}$ An. stephensia): 2 Knockdown activity b) MoA: GABA and PPO

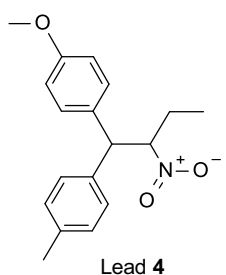

Origin: Ciba-Geigy A.-G. DE 2404914, 1974 [8] LC 80 An. stephensia): 2 Knockdown activity $\left.{ }^{b}\right)$

MoA: Na channel modulator<smiles>CN(/N=C(\C#N)c1ccc(C(F)(F)F)cc1)c1c(Cl)cc([N+](=O)[O-])cc1Cl</smiles>

Origin: Novartis

WO 9803475 [11]

LC 80 An. stephensia): 2

No knockdown activity

MoA: Uncoupler of oxidative phosphorylation

$$
\text { O" }
$$

Lead 10

Origin: $\mathrm{ICI}$

GB 2222157, 1990 [14]

$\mathrm{LC}_{80}$ An. stephensia): 2

No knockdown activity

MoA: Acetylcholine esterase inhibitor

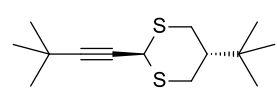

Lead 2

Origin: Wellcome Foundation University of California, Berkley EP 294229, 1988 [6] LC 80 An. stephensia): $\leq 0.2$ Knockdown activity ${ }^{\text {b) }}$ MoA: GABA

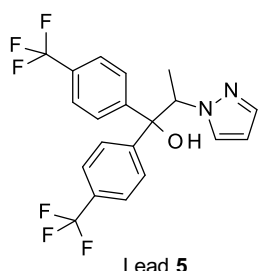

Origin: $\mathrm{ICI}$

EP 194064, 1986 [9] $\mathrm{LC}_{80}$ An. stephensia): 2 Knockdown activityb) MoA: Na channel modulator

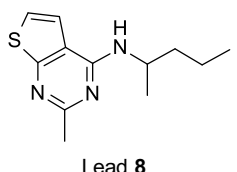

Origin: $\mathrm{ICl}$

DE 2654090, 1977 [12] LC $_{80}$ An. stephensia): 2 Knockdown activityb)

MoA: Mitochondrial complex I electron transport inhibitor

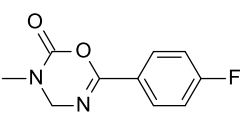

Lead 11

Origin: Ciba-Geigy A.-G DE 2459413, 1975 [15]

$\mathrm{LC}_{80}$ An. stephensia): 20 No knockdown activity ${ }^{b}$ MoA: Unknown

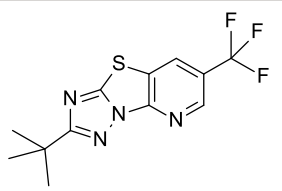

Lead 3

Origin: Sumitomo

JP 61015886, 1986 [7]

$\mathrm{LC}_{80}$ An. stephens $i^{\mathrm{a})}: \leq 0.2$

Knockdown activityb)

MoA: GABA

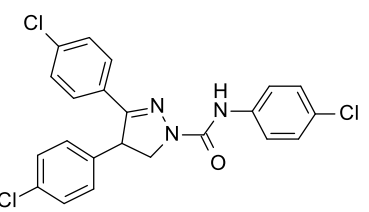

Lead 6

Origin: N. V. Philips' Gloeilampenfabrieken DE 25296891976 [10]

$\mathrm{LC}_{80}$ An. stephensia): 20

No knockdown activity

MoA: Na channel modulator

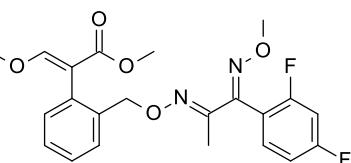

Lead 9

Origin: Novartis

WO 9720809 [13]

LC80 An. stephens;a): 20

No knockdown activity ${ }^{b}$

MoA: Mitochondrial complex III

electron transport inhibitor

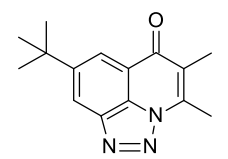

Lead 12

Origin: Meiji Seika Kaisha WO 2002060901 [16]

LC 80 An. stephensia): 20

No knockdown activity ${ }^{\text {b) }}$ MoA: Unknown
Fig. 1. Selection of identified leads for the control of adult mosquitoes with activity against Aedes aegypti and Anopeles stephensi. a) $\mathrm{LC}_{80}$ in mg Al. litre ${ }^{-1}$ against Anopheles stephensi after $48 \mathrm{~h}$ - lowest measured concentration at which at least $80 \%$ of the mosquitoes were killed. b) Knockdown against Anopheles stephensi determined after $1 \mathrm{~h}$; concentration $\leq$ $200 \mathrm{mg} \mathrm{Al} \mathrm{litre}^{-1}$ at which at least $80 \%$ of the mosquitoes showed knocked-down.

port inhibitors and acetylcholinesterase (AChE) inhibitors. The modes of action of two of the leads are not yet known, and could be potentially novel.

It is noteworthy to mention that lead $\mathbf{1}$ was originally prepared as part of a PPO herbicide project (diphenyl ethers) and lead 9 was synthesised as part of a complex III fungicide project (strobilurins). This indicates that representatives of certain herbicide and fungicide projects and modes of action can also be considered as valuable sources for leads for malaria vector control.

As a first lead for further optimization we selected the diphenyl ether compound 1. Lead 1 and several analogues showed in the lead identification phase very high potency against Aedes aegypti and Anopheles stephensi, including knockdown effect (Table 1).

\section{Optimization of Diphenyl Ether Lead 1}

The diphenyl ethers are a class of herbicides introduced to the market in the late 1970s and 1980s. These compounds act via inhibition of protoporphyrinogen oxidase (PPO), an enzyme involved in chlorophyll

Table 1. Activity of lead compounds against Aedes aegypti and Anopheles stephensi

\section{Compound}

\begin{tabular}{|c|c|}
\hline$D_{\text {80 }}^{\text {a }}$ \\
Adult \\
knockdown
\end{tabular}

200

Lead 2

$>200$

Lead 3

Lead 4

200

Lead 5

Lead 6

$>200$

Lead 7

$>200$

Lead 8

200

Lead 9

$>200$

Lead 10

$>200$

Lead 11

$>200$

$>200$
Aedes aegypti

$$
\mathrm{LC}_{80}{ }^{b}
$$

$\mathrm{LC}_{80}{ }^{\mathrm{b}}$

Adult mortality, Adult mortality, $24 \mathrm{~h}$ $48 \mathrm{~h}$

2

20

20

20

20

20

20

20

20

20
20

2

2

20

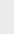

20

2

20

2

20

20

2

20

20
$\mathrm{KD}_{\mathbf{8 0}}{ }^{\mathrm{a}}$

Adult knockdown

20

200

20

2

$>200$

$>200$

200

$>200$

$>200$

$>200$

$>200$
Anopheles stephensi

$$
\mathrm{LC}_{80}{ }^{\mathrm{b}} \quad \mathrm{LC}_{80}{ }^{\mathrm{b}}
$$

Adult mortality, Adult mortality, 24 $48 \mathrm{~h}$

2

2

$\leq 0.2$

$\leq 0.2$

$\leq 0.2$

$\leq 0.2$

2

2

2

2

20

20

2

20

20

2

2

20

200

${ }^{\mathrm{a}} \mathrm{KD}_{80}$ in $\mathrm{mg} \mathrm{Al} \mathrm{litre}{ }^{-1}$ after $1 \mathrm{~h}$ - lowest measured concentration at which at least $80 \%$ of the mosquitoes showed knocked-down effects; ${ }^{b} \mathrm{C}_{80}$ in mg Al litre ${ }^{-1}$ after $24 \mathrm{~h}$ or $48 \mathrm{~h}$ - lowest measured concentration at which at least $80 \%$ of the mosquitoes were killed. 
biosynthesis. The leading product in this chemical class is fomesafen $\mathbf{1 3}$ (Fig. 2), which originated from a research program performed by ICI and was introduced to the market by Zeneca (now Syngenta) in 1982 for the post-emergence control of broadleaved weeds in soybeans. Research was undertaken in this herbicidal chemical class by many agrochemical companies until the mid 1990s, however, no new products have been introduced since 1992 . The diphenyl ether chemical class was also of interest to the public health insecticide research team at ICI during the 1980s, although again, no products were developed.

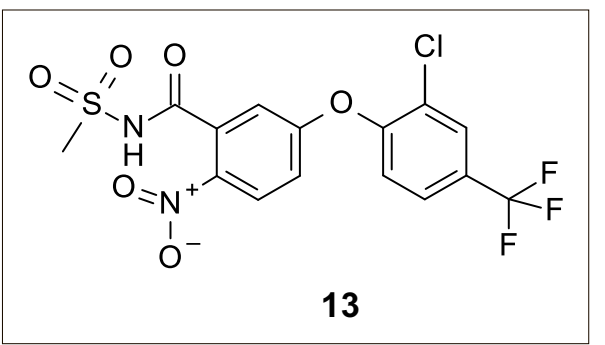

Fig. 2. Structure of Syngenta's diphenyl ether herbicide fomesafen 13.

Fomesafen 13 did not show activity against adult Aedes aegypti at the highest tested concentration (200 mg AI litre ${ }^{-1}$ ). However, some analogues prepared in the course of ICI's optimization program on diphenyl ethers, such as compound 1, displayed good activity against Aedes aegypti and Anopheles stephensi (Table 1). Initial resistance testing performed with lead $\mathbf{1}$ indicated some cross resistance risks and suggested that $\mathbf{1}$ and some analogues have activity at the GABA receptor, beyond binding to the herbicidal PPO target site. This dual mode of action was later confirmed by further studies.

In recent years Sumitomo has also investigated diphenyl ethers as mosquitocides. They focused on oxime substituents on the A-ring showing biological activity against Culex pipiens pallens. ${ }^{[17]}$

\subsection{Optimization Design}

In order to improve the biological activity and to clarify the resistance risk we started an optimization program to evaluate the influence of the substituents on the phenyl rings, the replacement of the phenyl rings by heterocycles and modifications of the oxygen ether linkage (Fig. 3). Following this design approach a series of new analogues were synthesised for testing against mosquitoes. Furthermore, selected additional historic analogues from our in-house collection were included in our evaluation to secure best coverage of the intended chemical scope.

\subsection{Synthesis}

In general the diphenyl ethers could be prepared by the replacement of one fluoro atom in substituted benzenes with a phenol. For example, treatment of $\mathbf{1 5}$ with the phenol 14 in DMF at $100^{\circ} \mathrm{C}$ in the presence of $\mathrm{K}_{2} \mathrm{CO}_{3}$, afforded the lead compound $\mathbf{1}$ in $57 \%$ yield (Scheme 1). ${ }^{[5,18]}$

Alternatively certain diphenyl ethers, such as compound 19, were prepared by reacting the phenol 17 with the boronic acid 18 using modified Chan-Lam coupling conditions (Scheme 2). ${ }^{[19,20]}$

The carbon-bridged compounds were synthesised as shown in Scheme 3. Deprotonation of compound $\mathbf{2 0}$ and reaction of the resulting anion with carbon dioxide delivered the acid 21, ${ }^{[21]}$ which was transformed into the acid chloride. FriedelCrafts acylation gave the ketone $\mathbf{2 2}$ which was subsequently nitrated in the meta-position. Reduction of the ketone delivered the alcohol $\mathbf{2 4}$ which could be methylated or transformed into the fluoro analogue $\mathbf{2 6}$.

\subsection{Results}

All compounds were tested first against Aedes aegypti and if they showed activity at $200 \mathrm{mg} \mathrm{AI} \mathrm{litre}{ }^{-1}$ or at lower concentrations they were tested against Anopheles stephensi. The structure-activity relationship of the B-ring was found to be very steep (Fig. 4). Best biological activity was obtained with halogen atoms, chlorine or fluorine, in the 2- and 6-positions and a trifluoromethyl group in the 4-position of the B-ring. Other modifications led to a reduction or a loss of mosquitocidal activity, for example the replacement of the trifluoromethyl group by a trifluoromethoxy group, a chlorine, a bromine, a methoxy group or other substituents. Compounds containing only one ortho-chloro substituent showed significantly reduced mosquitocidal activity. Compounds with no substituents in the ortho-positions were inactive against mosquitoes. Methyl groups or bromine substituents in the 2,6-position of the B-ring resulted in a loss of biological activity. Analogues in which the phenyl ring was replaced by a pyridyl or a pyridyl $\mathrm{N}$-oxide were inactive.

Compounds containing an oxygen-bridge generally showed greatest biological activity, although the compounds containing a carbonyl-bridge - depending on the substitution pattern - sometimes showed comparable biological activity. Other bridges led to a reduction or a loss of the mosquitocidal activity (Fig. 5).

A broad range of compounds with

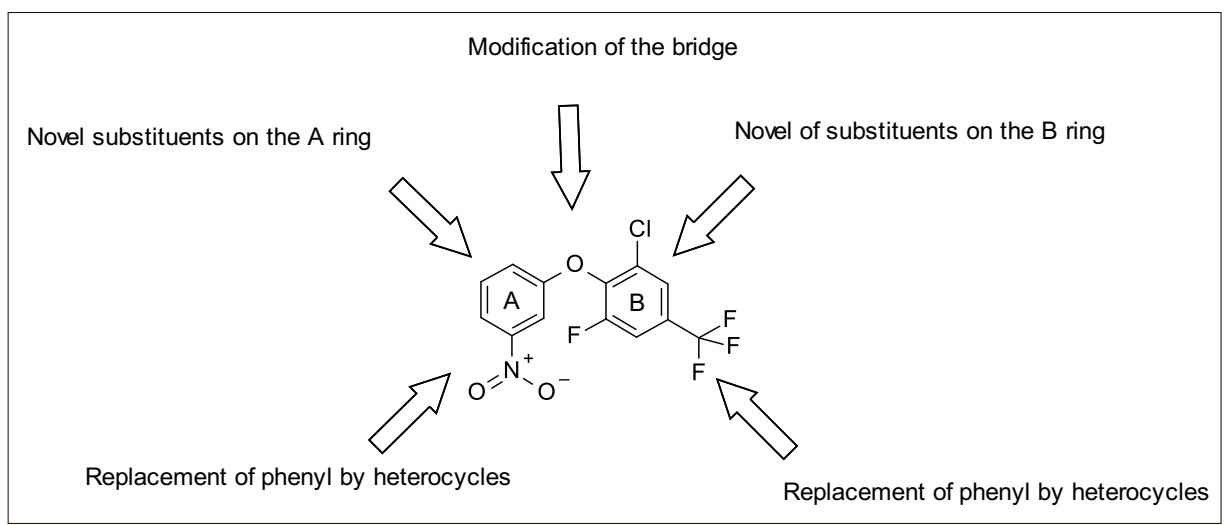

Fig. 3. Design of novel diphenyl ethers.

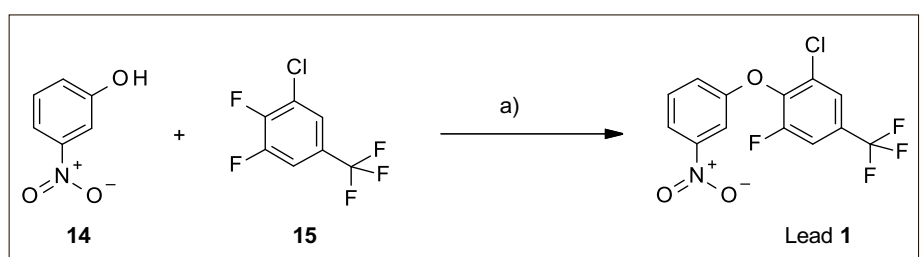

Scheme 1. General synthesis of diphenyl ethers - Method 1. Reagents and conditions: a) $\mathrm{K}_{2} \mathrm{CO}_{3}$, DMF, $100{ }^{\circ} \mathrm{C}, 20 \mathrm{~h}(57 \%)$.

14
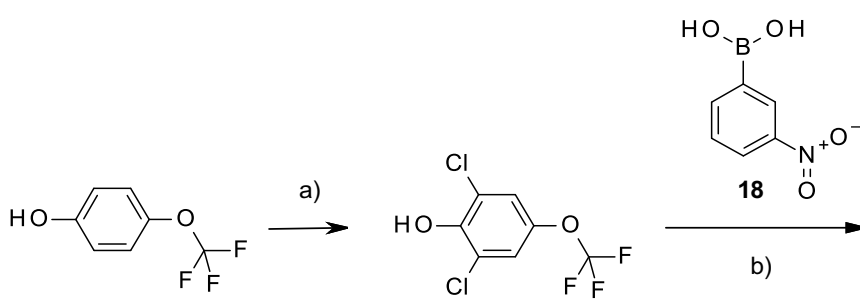

$18 \stackrel{11}{O}$

b)

17

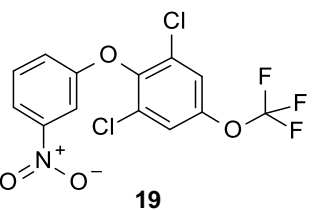

Scheme 2. General synthesis of diphenyl ethers - Method 2. Reagents and conditions: a) $\mathrm{Cl}_{2}$ $\mathrm{CHCl}_{3}, 0^{\circ} \mathrm{C}, 1.5 \mathrm{~h}(91 \%) ;$ b) oxygen, 0.05 equiv. Cu powder, 2 equiv. pyridine, $\mathrm{CH}_{2} \mathrm{Cl}_{2}, \mathrm{rt}, 16 \mathrm{~h}$ (21\%). 


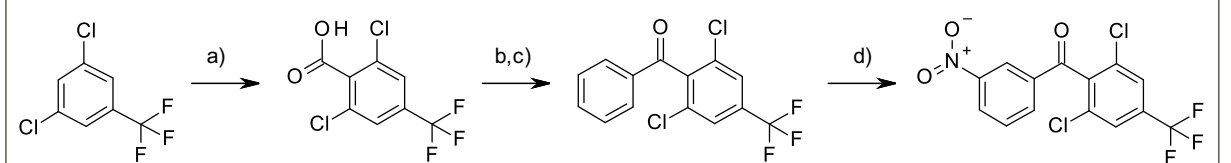<smiles>COC(c1cccc([N+](=O)[O-])c1)c1c(Cl)cc(C(F)(F)F)cc1Cl</smiles>

22

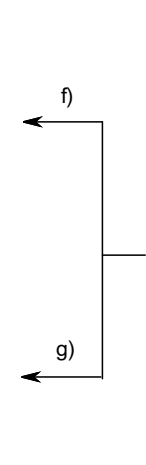

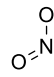

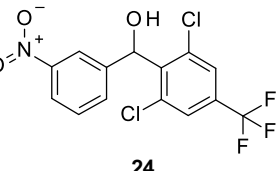

26
Scheme 3. Synthesis of carbon-bridged compounds. Reagents and conditions: a) BuLi, THF, dry ice (82\%); b) oxalylchloride, $\mathrm{CH}_{2} \mathrm{Cl}_{2}$, $\mathrm{DMF}_{\text {cat: }}$ c) benzene, $\mathrm{AlCl}_{3}(69 \%, 2$ steps); d) guanidine nitrite, $\mathrm{H}_{2} \mathrm{SO}_{4}(79 \%)$; e) $\mathrm{NaBH}_{4}$, $\mathrm{MeOH}(92 \%)$; f) $\mathrm{NaH}$, Mel, DMF (49\%);

g) [Bis(2-methoxyethyl)amino] sulfur trifluoride, $\mathrm{CH}_{2} \mathrm{Cl}_{2}(40 \%)$.

different substituents in the A-ring were investigated. Many different substitution patterns with electron-withdrawing substituents or electron-donating substituents resulted in biological activity against mosquitoes. On the other hand many substitution patterns led to inactive molecules. The greatest activity against susceptible Aedes aegypti and Anopheles stephensi was observed with compounds containing a nitro group in the 3- or in the 4-position. Also some compounds with 4-cyano groups showed good mosquitocidal activity (Fig. 6).

Unfortunately the highly active compounds containing a nitro-group at the 3 - or 4-position, for example compounds 1 and 27 or a 3-acetyloxy group, such as compound 28, showed high levels of cross-resistance against an $r d l$-resistant Anopheles gambiae strain (Kisumu rdl). As hypothesised, we could identify subclasses which show reduced or no cross-resistance, for example the 4-methylthio subclass with compound 29 as prominent example, or the 4-cyano subclass, as exemplified by compound 30. However, their potency was generally lower. The exception and best compound identified during our optimization program was the cyano-pyridyl compound 31 which exhibited good activity against all tested mosquito species including rdl-resistant Anopheles gambiae (Fig. 7, Table 2). Compound 31 was only slightly weaker than permethrin and did not show relevant cross-resistance to the organochlorine insecticide dieldrin, a compound acting, like our diphenyl ethers, at the GABA-chloride receptor channel complex.

\section{Summary and Conclusions}

Malaria occurs in approximately 100 countries worldwide and today, a significant proportion of the world's population still remains at risk from malaria vector borne disease. Current tools and treatments are not yet sufficient to achieve the desired goal of malaria elimination. Furthermore resistance in the vector populations, principally to pyrethroids, is developing, requesting the development of new tools for malaria vector control.

In order to identify new leads for malaria vector control we have started a research program in collaboration with the Innovative Vector Control Consortium (IVCC). A new screening platform involv-

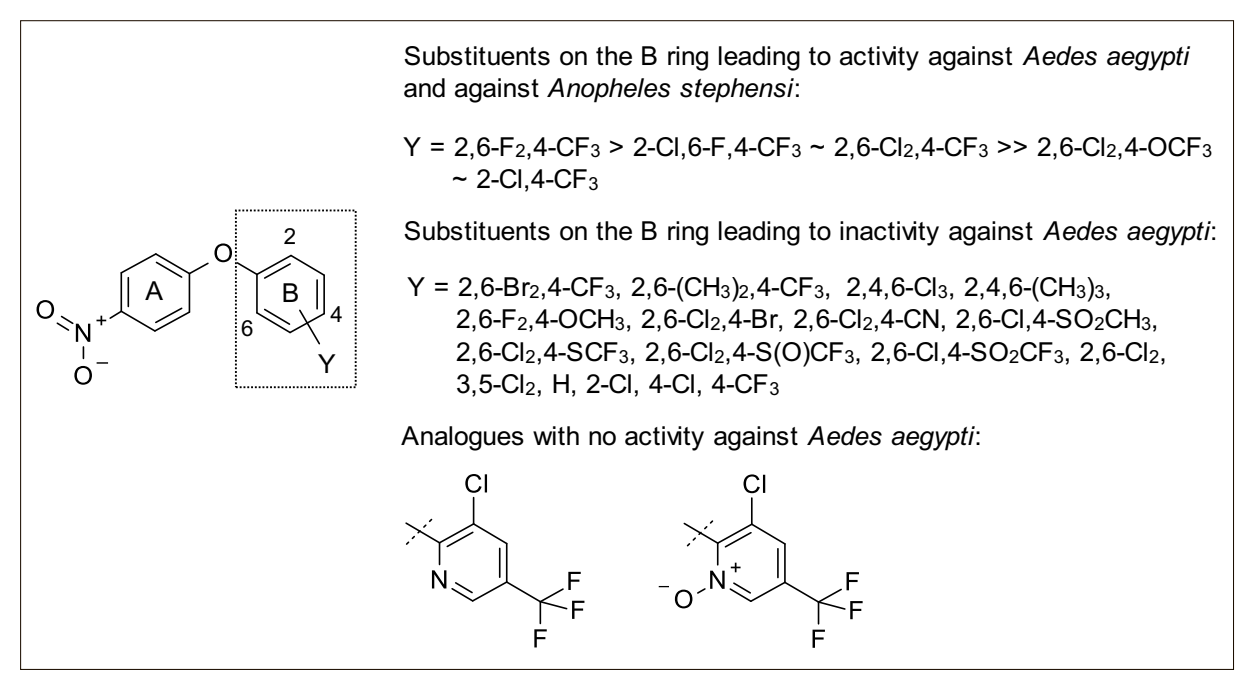

Fig. 4. Modifications in the B-ring - Structure-activity relationships.

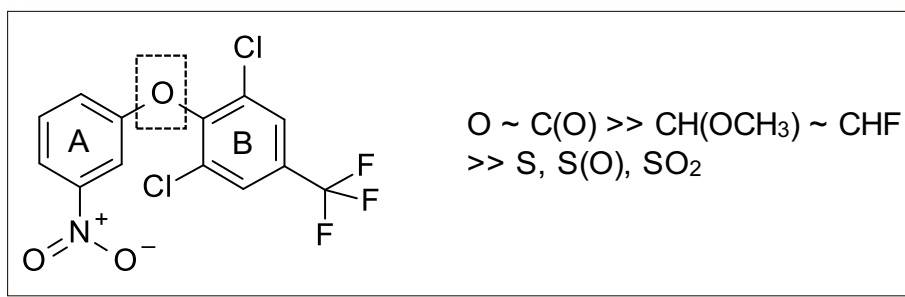

Fig. 5. Modifications in the bridge Structure-activity relationships.

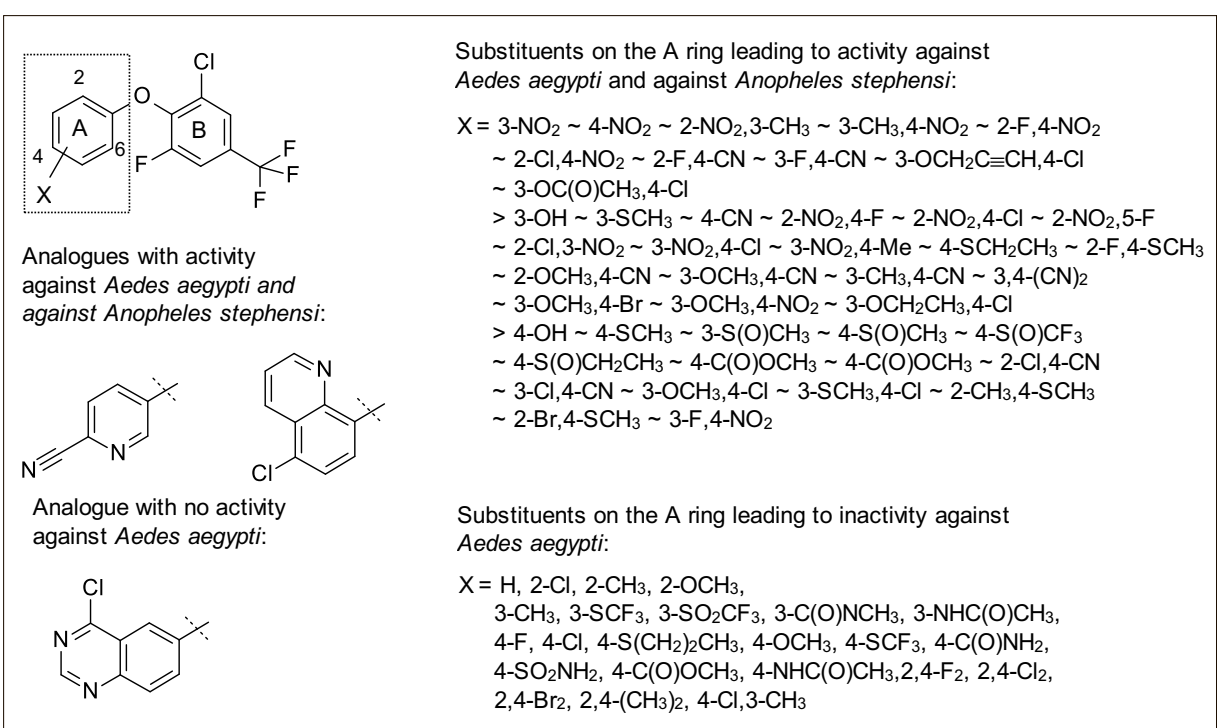

Fig. 6. Modifications of the A-ring - Structure-activity relationships. 
Compounds showing high levels of cross-resistance:<smiles>CO[N+](=O)c1cccc(Oc2c(F)cc(C(F)(F)F)cc2Cl)c1</smiles>

Lead 1<smiles>O=[N+]([O-])c1ccc(Oc2c(F)cc(C(F)(F)F)cc2Cl)cc1</smiles>

27

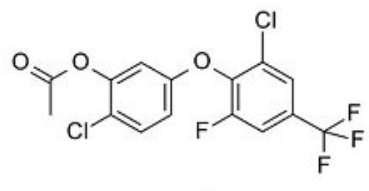

28
Compounds showing low levels of cross-resistance:

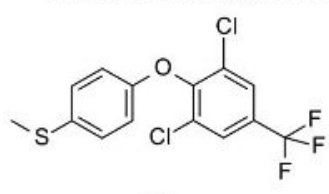

29<smiles>N#Cc1ccc(Oc2c(F)cc(C(F)(F)F)cc2Cl)cc1</smiles>

30

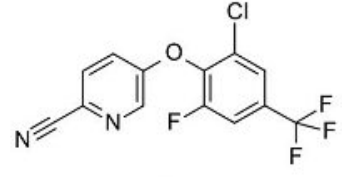

31
Fig. 7. Best diphenyl ethers identified during the optimization program. ing bioassays against adult Aedes aegypti and Anopheles stephensi has been developed and more that 30,000 compounds from the Syngenta corporate chemical collection were tested. More than 3000 compounds $(10 \%)$ were found to be active at $\leq 200 \mathrm{mg}$ AI litre ${ }^{-1}$ against adult Aedes aegypti. Clustering of the actives and evaluating them against a set of criteria defined for a viable lead, resulted in the identification of 12 viable leads for the control of adult mosquitoes, most originating from current or former insecticides projects. It is noteworthy to mention that one lead emerged from a PPO herbicide project (chemical class: diphenyl ethers) and another one from a complex III fungicide project (chemical class: strobilurins). This indicates that representatives of certain herbicide and fungicide projects and modes of action can also represent a valuable source for leads for malaria vector control.

Furthermore, the optimization of the diphenyl ether lead $\mathbf{1}$ is described. A series of diphenyl ethers with good activity against malaria mosquito vectors were prepared applying standard synthetic methodology. The cyano-pyridyl compound
31 was identified as the best compound resulting from our diphenyl ether optimization program. 31 exhibited good activity against all mosquitos evaluated, including rdl resistant Anopheles. It was only slightly less potent than permethrin and did not show cross-resistance to the organochlorine insecticide dieldrin. Additional work would be necessary to improve potency and to further understand the potential for cross-resistance risks, before this chemical class could deliver a new tool for malaria vector control. Progress on our research on other leads will be reported elsewhere.

\section{Acknowledgments}

The authors would like to thank Dr. Michael Turnbull, Dr. Hans Brunner and Mr. Heinz Binder for helping to generate prospective screening inputs, Mr. Laurent Villebrun for assistance in the synthesis of the diphenyl ether compounds, Mr. Israel Tsegaye Beyene and Ms. Nicoleta Daems for their valuable assistance in undertaking the bioassays presented in this paper. We also thank the Innovative Vector Control Consortium, especially Prof. Dr. Trevor Perrior, Dr. Colin Ruscoe, Dr. Robert Sloss and Dr. Sarah Rees for fruitful discussions and a great collaboration over the past few years.
[1] Global Malaria Action Plan - Roll Back Malaria: $\quad$ www.rollbackmalaria.org/micrositel gmap/1-2.html, accessed August 25, 2016.

[2] The Global Malaria Action Plan - Key Facts, Figures and Strategies, 2008, www.rollbackmalaria.org/microsites/gmap/GMAP_Advocacy-ENG-web.pdf, accessed August 25, 2016.

[3] Globalplanforinsecticideresistancemanagement in malaria vectors, 2012, www.who.int/iris/ bitstream/10665/44846/1/9789241564472_ eng.pdf, accessed August 25, 2016.

[4] H. Van den Berg, M. Zaim, R.S. Yadav, A. Soares, B. Ameneshewa, A. Mnzava, J. Hii, A. Prasad Dash, M. Ejov, Environ. Health Perspect. 2012, 120, 577.

[5] J. E. D. Barton, Imperial Chemical Industries, EP 355049 A2, 1990.

[6] J. E. Casida, M. Elliott, D. A. Pulman, Wellcome Foundation Ltd., UK, University of California, Berkeley, EP 294229 A2, 1988.

[7] Y. Nakayama, T. Yano, H. Takeda, Sumitomo Chemical Co., JP 61015886 A, 1986.

[8] B. Boehner, D. Dawes, W. Meyer, Ciba-Geigy A.-G., DE 2404914 A1, 1974.

[9] M. J. Bushell, Imperial Chemical Industries, EP 194064 A2, 1986.

[10] J. J. Van Daalen, R. N. V. Mulder, Philips' Gloeilampenfabrieken, DE 2529689 A1, 1976.

[11] F. Karrer, R. G. Hall, Novartis AG, WO 9803475 A1, 1998.

[12] J. M. Cox, J. H. E. Marsden, R. A. Burrell, N. Elmore, M. C. Shephard, Imperial Chemical Industries, DE 2654090 A1, 1977.

[13] S. Farooq, S. Trah, H. Ziegler, R. Zurfluh, A. Pascual, H. Szczepanski, R. G. Hall, Novartis AG, WO 9720809 A1, 1997.

[14] M. J. Bushell, R. A. E. Carr, D. W. Moseley, N. C. Sillars, Imperial Chemical Industries, GB 2222157 A, 1990.

[15] R.K.Huff,Ciba-GeigyAG,DE2459413A1,1975

[16] K. Oyama, T. Teraoka, K. Yamamoto, Meiji Seika Kaisha, WO 2002060901 A1, 2002.

[17] H. Miyazaki, H. Uneme, Y. Katagiri, Y. S. A-K. Sokeirik, G. B. Salunke, Sumitomo, JP 2014080385, 2014.

[18] R. Takahashi, K. Fujikawa, I. Yokomichi, T. Toki, S. Someya, Ishihara Mining and Chemical Co., DE 2304006 A1, 1973.

[19] D. M. T Chan, Tetrahedron Lett. 1998, 39, 2933.

[20] N. Debreczeni, A. Fodor, Z. Hell, Catalysis Lett. 2014, 144, 1547.

[21] E. Masson, E. Marzi, F. Cottet, C. Bobbio, M Schlosser, Eur. J. Org. Chem. 2005, 20, 4393.

Table 2. Activity of diphenyl ether compounds against Anopheles stephensi and against rdl-resistant Anopheles gambiae Kisumu strain

\begin{tabular}{|c|c|c|c|c|c|c|c|}
\hline \multirow[t]{2}{*}{ Compound } & \multicolumn{3}{|c|}{ Anopheles stephensi } & \multicolumn{3}{|c|}{ rdl-resistant Anopheles gambiae Kisumu } & \multirow{2}{*}{$\begin{array}{c}\text { Resistance } \\
\text { Factor }\end{array}$} \\
\hline & $\begin{array}{c}\mathrm{KD}_{80}{ }^{\mathrm{a}} \\
\text { Adult } \\
\text { knockdown }\end{array}$ & $\begin{array}{c}\mathrm{LC}_{80}{ }^{\mathrm{b}} \\
\text { Adult } \\
\text { mortality, } \\
\mathbf{2 4} \mathrm{h}\end{array}$ & $\begin{array}{c}\mathrm{LC}_{80}{ }^{\mathrm{b}} \\
\text { Adult } \\
\text { mortality, } \\
\mathbf{4 8 ~ h}\end{array}$ & $\begin{array}{c}\mathrm{KD}_{80}^{\mathrm{a}} \\
\text { Adult } \\
\text { knockdown }\end{array}$ & $\begin{array}{c}\text { LC }_{80}{ }^{b} \\
\text { Adult } \\
\text { mortality, } \\
24 \text { h }\end{array}$ & $\begin{array}{c}\text { LC }_{80}{ }^{b} \\
\text { Adult } \\
\text { mortality, } \\
48 \mathrm{~h}\end{array}$ & \\
\hline Lead 1 & 200 & 20 & 20 & $>200$ & $>200$ & 200 & $\sim 10$ \\
\hline 27 & 200 & 20 & 20 & $>200$ & $>200$ & $>200$ & $>10$ \\
\hline 28 & $>200$ & 2 & 2 & $>200$ & 200 & 200 & 100 \\
\hline 29 & $>200$ & 200 & 200 & $>200$ & 200 & 200 & 1 \\
\hline 30 & 200 & 20 & 200 & 200 & 20 & 20 & 1 \\
\hline 31 & 200 & 2 & 2 & 50 & 6.25 & 6.25 & $\sim 4$ \\
\hline Permethrin & $>200$ & 2.5 & 1.25 & $>200$ & 1.25 & 1.25 & $\sim 1$ \\
\hline Dieldrin & $>200$ & 0.2 & 0.2 & $>200$ & 20 & 20 & 100 \\
\hline
\end{tabular}

${ }^{\mathrm{a}} \mathrm{KD}_{80}$ in $\mathrm{mg} \mathrm{Al} \mathrm{litre}{ }^{-1}$ after $1 \mathrm{~h}$ - lowest measured concentration at which at least $80 \%$ of the mosquitoes showed knocked-down effects; ${ }^{\text {bC }}{ }_{80}$ in mg a.i. litre ${ }^{-1}$ after $24 \mathrm{~h}$ or $48 \mathrm{~h}$ - lowest measured concentration at which at least $80 \%$ of the mosquitoes were killed. 